\title{
Biomotor Ability Profile of Indonesian Male Rugby Athletes For Asian Games 2018
}

\author{
$1^{\text {st }}$ Junaidi \\ Fakultas Ilmu Keolahragaan \\ Universitas Negeri Jakarta. \\ junaidi_sportmed@unj.ac.id
}

\begin{abstract}
Description in this research is the use of Muscle strength, Explosive power, Cardio endurance, Flexibility and Coordination as a measure of athlete biomotor ability at male athletes. Measurement their Biomotor ability held at the Faculty of Sport Science of Jakarta State University. The research findings the Biomotor Ability Profile of Indonesian Male Rugby Athletes for Asian Games 2018 are; Good muscle strength 9 (50\%), Average muscle strength $7 \mathbf{( 3 8 . 8 \% )}$, Less muscle strength $2(11.2 \%)$; Good explosive power $16(89 \%)$, Average explosive power $1(5.5 \%)$, Less explosive power 1 (5.5\%); Good cardio endurance $0(0 \%)$, Average cardio endurance $0(0 \%)$, Less cardio endurance $18(100 \%)$; Good flexibility $1(5.5 \%)$, Average flexibility $14(77.8 \%)$, Less flexibility $3(16.7 \%)$; and Good coordination $9(50 \%)$, Average coordination $5(27.7 \%)$, Less coordination $4(22.3 \%)$. The conclusion of this study are; Muscle strength, explosive power, flexibility and coordination at Indonesian Male Rugby Athletes for Asian Games 2018 are good meanwhile their cardio endurance are less.
\end{abstract}

Keywords-Biomotor ability; muscle strength, explosive power, cardio endurance, flexibility, coordination and rugby athletes

\section{INTRODUCTION}

Most sport activities can be classified as having a pre dominant biomotor ability. Every sport activity has dominant biomotor ability. However, contemporary research suggests that sport activities can be affected by several biomotor abilities. It can be clearly seen by the fact that muscular strength appears to influence both running speed and endurance at rugby athlete. Leg strength and power appear to be significantly related to sprint speed, with the strongest and most powerful at rugby athletes being able to run fastly. In fact, rugby athlete performance is dominated by combinations of strength, speed, endurance, flexibility and balancing. The objective of this research is to obtain information the Biomotor Ability Profile of Indonesian Male Rugby Athletes for Asian Games 2018.

\section{MATERIAL AND METHOD}

\section{A. Biomotor Ability}

Biomotor ability are critical factors in deter $\neg$ mining success in a wide variety of sports. For example, muscular strength and power are generally acknowledged as being important in all team sports and sports that are dominated by speed, not exception rugby team sport. Bompa coined 8 biomotor abilities. (Speed, Strength, Endurance, Coordination, Balance, Power, Flexibility and Agility). 8 biomotor ability would be the GOLD Standard for that ability. This means the best human being we have seen at this ability

Muscle Strength. Strength can be defined as the maximal force or torque (rotational force) a muscle or muscle group can generate. Strength is better defined as the ability of the neuromuscular system to produce force against an external resistance. Contemporary literature suggests that high levels of muscular strength are significantly related to sport performance. For example, muscular strength has been related to sprint performance at rugby playing. Therefore, the appropriate application of resistance training can alter the neuromuscular system in a way that improves the athlete's capacity to produce force and improves sports performance.

The maximal strength that an athlete can exhibit depends on seven key concepts: (a) the number of motor units involved (recruitment), (b) the motor unit firing rate (rate coding), (c) the amount of motor unit synchronization, (d) the use of the stretch shortening cycle, (e) the degree of neuromuscular inhibition, (f) the muscle fiber type, and (g) the degree of muscle hypertrophy.

The terms strength is widely used to describe some important abilities that contribute to maximal human efforts in sport and other physical activities. Unfortunately, there is often little consistency in the way the terms are used. Though it is widely accepted that strength is the ability to exert force, there is considerable disagreement as to how strength should be measured. The weight that a person can lift is probably the oldest quantitative measure of strength. Technological developments have popularized the use of isometric strength testing and, more recently, isokinetic strength testing.The coach and athlete must understand how the development of strength can affect performance. The coach and athlete need to understand the principles associated with resistance training to effectively use resistance training to enhance performance. Measurement muscle strength used grip, pull/push, leg and back.

Explosive Power is precisely defined as the rate of doing work, where work is the product of the force exerted on an object and the distance the object moves in the direction in which the force is exerted. Quantitatively, work and power are defined as:

- $\quad$ Work $=$ Force $\mathrm{x}$ Distance 
- $\quad$ Power $=$ Work/Time

Power can also be defined as

- $\quad$ Power $=$ Force $\mathrm{x}$ Velocity

So power is the product of the force exerted on an object and the velocity of the object in the direction in which the force is exerted. Or simply put, power describes force with respect to time. Biomotor abilities strength and speed combine to create power. An athletes can be strong and able to move a heavy load but not necessarily powerful where an athletes would move the load rapidly. Movements such as vertical jumps, standing broad jumps, different types of tossing, passing or throwing with medicine balls (measuring the distance thrown or jumped) can all be used to test power

The rate of force development is at the maximum for any type of muscle action is explosive power. In activities requiring high acceleration and output, explosive power training is necessary for maximum development. Some examples of these activities would include soccer, hurdling and football. This type of training is effective in enhancing athletic performance.

The general exerciser doesn't usually need to include explosive power training in a regular workout. Cardiovascular and strength training in a slow, steady manner will give adequate results. In contrast, Athletic movements need to be performed at high speeds. The muscles have to be developed and trained outside of the sport in order to do this. The types of exercises used in explosive power training are determined by the type of sport that is being trained for. For example, for a rugby player trying to improve his jump shot would have a training program that would include weighted vertical jumps.

Explosive power exercises should be taught and supervised by fitness professionals to reduce the risk of injury. They should also be done in conjunction with a regular workout program to ensure that the athlete is balanced in all exercise areas

To develop explosive power need to do two things. First, build speed and strength. An athletes must raise absolute strength. A shot putter must become stronger and at the same time, faster. The majority of this training is combining max effort exercises to increase the strength potential of the muscles, while training with light weights will lead to improving speed.

To improve explosive power, the movement must change from eccentric to a concentric action. One popular method is the Plyometrics method. For this, depth jumps are in order. This calls for the athlete to fall from a distance and upon landing, immediately jump upward in under 0.2 seconds. This is reversible muscular action or the stretch-shortening cycle. It is used in most sports skills due to muscle and tendon elasticity. The athlete must use the correct movement velocities.

Cardio Endurance can be classified several ways. For example, aerobic endurance, sometimes called low-intensity exercise endurance, allows a person to perform activities continually for a long duration, whereas anaerobic endurance, or high-intensity exercise endurance, provides the ability to repetitively perform bouts of high-intensity exercise. Although most sports rely on some form of endurance, the type of endurance developed (high or low intensity) can significantly affect performance outcomes. Therefore, the coach and athlete must consider the type of endurance that the athlete needs for the sport and how the appropriate endurance will be targeted within the training plan. The coach and athlete must also consider the athlete's physiological responses to the methods for developing endurance. Once the type of endurance and the physiological responses are understood, the coach can develop a training plan to enhance sport-specific endurance.

The concept of endurance differs distinctly between various sporting activities and thus can be defined in several different ways. For example, the type of endurance that an marathon runner athletes needs provides the ability to continuously perform at a specific power output or velocity for a long duration of time. Conversely, a rugby player needs to repetitively perform periods of high-velocity movements for several time with periods of recovery. Although some form of endurance affects both athletes' performance, the development of endurance in these athletes will be distinctly different. If the wrong type of endurance training is implemented, the athlete might develop endurance characteristics that do not meet the needs of the sport, and thus performance capacity can be reduced. To understand the correct application of endurance training, the coach and athlete must differentiate between the two major types of endurance reported in the contemporary literature: low-intensity exercise endurance (LIEE) and highintensity exercise endurance (HIEE).

Activities that are predominated by aerobic energy supply tend to exhibit lower peak powers and thus can be classified as being of lower intensities. These activities require the athlete to perform continually, at a low intensity, for a substantial duration. Thus, this type of endurance is often termed LIEE or aerobic endurance.

Sports that rely on anaerobic metabolism usually require high power outputs or the repetitive performance of highvelocity movements. Because anaerobic activities require higher power outputs than those seen in aerobic activities, anaerobic activities can be classified as being of high intensity. Therefore, the ability to sustain and repeat high-intensity exercise bouts is considered to be HIEE. The development of HIEE does not impair strength and power-generating capacity, as typically occurs when LIEE is developed.

Flexibility can be defined as the range of motion about a body joint. It refers to the state of the muscle's length, which restricts or allows freedom of joint movement. Flexibility is essential for optimum joint and muscle function. There are many excellent books on assessing muscle length and tension as well as joint function. Typical devices for measuring flexibility include manual and electric goniometers, which measure joint angle, and the sit-and-reach box, which is used to evaluate the combined flexibility of the lower back and hips. Flexibility measurements are more reliable when standardized warm-up and static stretching pre $\neg$ cede the flexibility assessment. During a flexibility test, the athlete should move slowly into the fully stretched position and hold this position. Ballistic stretching, characterized by bouncing to increase 
range of motion, should be prohibited during warm-ᄀup and cannot be allowed during any flexibility testing.

Flexibility refers to the range of movement in a joint or series of joints, and length in muscles that cross the joints to induce a bending movement or motion. Flexibility varies between individuals, particularly in terms of differences in muscle length of multi-joint muscles. Flexibility in some joints can be increased to a certain degree by exercise, with stretching a common exercise component to maintain or improve flexibility. Quality of performance is enhanced by improving and maintaining a good range of motion in the joints. Overall flexibility should be developed with specific joint range of motion needs in mind as the individual joints vary from one to another. Loss of flexibility can be a predisposing factor for physical issues such as pain syndromes or balance disorders.

Many factors are taken into account when establishing personal flexibility: joint structure, ligaments, tendons, muscles, skin, tissue injury, fat (or adipose) tissue, body temperature, activity level, age and sex all influence an individual's range of motion about a joint. Individual body flexibility level is measured and calculated by performing a sit and reach test, where the result is defined as personal flexibility score.

Coordination is a complex ability and correlates closely with strength, flexibility, speed and endurance. If an athletes have poor ability in any of these areas, this can limit their development of coordination. When improving coordination, their should emphasize developing a large variety of skills and progressively increase exercise complexity. Variety is important in exercise selection and equipment used. For example, it is beneficial in the development of coordination to have perform activities and skills with their non-dominant limbs.

To assess coordination, agility and balance, complex multi direction movements are useful. Using unilateral movements and balance tests are also helpful to determine the athletes' abilities in these areas. Take care to look at how quickly or slowly they perform the various movements, remembering that the physiological basis of coordination relies heavily on the coordination of the various processes of the central nervous system.

\section{B. Rugby}

Rugby union like with many other team sports is a sport of intermittent activities of both high intensity and low intensity periods, with many gait changes performed during game phase. The ability to identify and understand the specific demands placed upon sports performers during match play and training situations has long since been recognized as a crucial factor in developing appropriate training and recovery program which may elicit improved performance. Important aspects for successful performance within rugby union match play include strength, power, speed and both aerobic and anaerobic capacity, with increases in size and strength amongst players noted to correlate with on field performance.

Increased commercial interest in rugby union since it became professional in 1995 has led to players receiving better analysis and management of training to optimize performance in matches, resulting in the game reported to becoming faster, containing more phases and involving bigger, faster and more physical players. A typical professional rugby season in the northern hemisphere contains over 30 games and involves blunt force trauma and high running volumes in training and matches

Rugby is a contact sport played over two 40-minute halves where high levels of force are both generated and absorbed upon impact. Teams are made of fifteen members, and players are divided into forwards and backs. The stereotype, with limited truth, is that forwards tend to be immobile and thrive on physicality. Their primary role is to secure possession of the ball. That's not to say, however, that attack is strictly off limits. In a game analysis conducted by the International Rugby Board, forwards completed an average $42 \%$ of passes at the 2011 Rugby World Cup. This shows that forwards are integral to an effective attack.

Conversely, if athletes have speed, power, and skill, they are often placed as backs. As rugby becomes increasingly dynamic, however, every player will need to be comfortable with the ball in hand and with making active defensive tackles.

Performance programs in rugby should center on the game's physiological, psychological, and logistical demands. While a periodized training plan might look perfect, rugby is far from perfect regarding movement. Set plays happen at high speed, and defensive players must decide how to best tackle the oncoming attackers. Predictable drills certainly have a part to play in practice, but it's important to progress toward more random drills.

Technical and tactical development have a direct relationship with the physical abilities also call biomotor abilities, the rugby player need to develop. These abilities include strength, speed, cardio endurance and coordination. The purpose of this paper is to present the profile of physiological Bio motor ability of Rugby athletes. In addition, it will critique my initial theories about the importance of the energy systems to this sport as well as ASEP's model. These critiques will be based on the findings of five peer-reviewed journal articles found using the SPORT Discus database. Due to the limited amount of resources and the absence of a Rugby specific model in the text, I also referred to Rugby since it is similar in many areas.

\section{RESUlt AND Discussion}

\section{Biomotor Ability Profile of Indonesian Male Rugby} Athletes

TABle. I. DAta of Muscle StRength

\begin{tabular}{|c|c|c|}
\hline Muscle Strength & Number & Percentage \\
\hline Good & 9 & $50 \%$ \\
\hline Average & 7 & $38.8 \%$ \\
\hline Less & 2 & $11.2 \%$ \\
\hline Total & $\mathbf{1 8}$ & $\mathbf{1 0 0 \%}$ \\
\hline
\end{tabular}

Identify applicable funding agency here. If none, delete this text box. 
TABLe. II. Data of Explosive Power

\begin{tabular}{|c|c|c|}
\hline Explosive Power & Number & Percentage \\
\hline Good & 16 & $89 \%$ \\
\hline Average & 1 & $5.5 \%$ \\
\hline Less & 1 & $5.5 \%$ \\
\hline Total & $\mathbf{1 8}$ & $\mathbf{1 0 0 \%}$ \\
\hline
\end{tabular}

TABLE III. DATA OF CARDIO ENDURANCE

\begin{tabular}{|c|c|c|}
\hline Cardio Endurance & Number & Percentage \\
\hline Good & 0 & 0 \\
\hline Average & 0 & 0 \\
\hline Less & 18 & $100 \%$ \\
\hline Total & $\mathbf{1 8}$ & $\mathbf{1 0 0 \%}$ \\
\hline
\end{tabular}

TABLE IV. DATA OF FLEXIBILITY

\begin{tabular}{|c|c|c|}
\hline Flexibility & Number & Percentage \\
\hline Good & 1 & $5.5 \%$ \\
\hline Average & 14 & $77.8 \%$ \\
\hline Less & 3 & $16.7 \%$ \\
\hline Total & $\mathbf{1 8}$ & $\mathbf{1 0 0 \%}$ \\
\hline
\end{tabular}

TABLE V. DATA OF COORDinAtion

\begin{tabular}{ccc}
\hline Coordination & Number & Percentage \\
\hline Good & 9 & $50 \%$ \\
\hline Average & 5 & $27.7 \%$ \\
\hline Less & 4 & $22.3 \%$ \\
\hline Total & $\mathbf{1 8}$ & $\mathbf{1 0 0 \%}$
\end{tabular}

\section{A.Discussion}

As sport participation becomes more competitive, the rugby athlete are required to have good biomotor abilities. Good biomotor abilities will support athletes achievement. From the data of muscle strength, data of explosive power, data of flexibility and data of coordination (table 1, 2, 4 and 5) showed are good results, contrarily data of cardio endurance (table 3) showed are less. This may due to the aerobic training method given have poor; involve the intensity and duration of the training.

Cardio endurance training is any activity that involves the large muscles of the body (especially the legs) or rhythmic and continuous in nature (as opposed to stop-andstart) so that challenges heart and lungs to work harder.
Activities like walking, jogging, running, cycling, swimming, aerobics, rowing, stair climbing, hiking, cross country skiing and many types of dancing are "pure" aerobic activities. Sports such as soccer, basketball, squash and tennis may also improve cardio endurance. However, cardio endurance training could improve performance in the sports include rugby. Athletes typically use three training methods to improve cardio endurance that is: 1). slow to moderate-intensity distance training, 2). moderate to high-intensity interval training, 3). high-intensity continuous training.

Mix high-impact activities like jogging or step aerobics with weight-supported activities like rowing and cycling can improve cardio endurance. The more muscles involved in the activity, the greater aerobic challenge. For example, cross country training have shown the highest aerobic capacity of all athletes. They vigorously use arms, legs and trunk muscles during training. One of the most important changes taking place during cardio endurance training is that working muscles become more efficient at taking in and using oxygen. If the athletes are getting ready for a rugby competition, the majority of preparation should involve running, using the muscles and motions are required. Running itself provides the best "sportspecific" conditioning for a rugby competition.

Tudor. O. Bompa has said that aerobic training intensity is 72 to $87 \%$ from maximal heart rate and duration of aerobic training is 30 minutes to 90 minutes and 3 times a week to guarantee increased aerobic capacity in about 8 to 12 weeks. Athletes utilizing high- intensity continuous training to increase their lactate threshold should exercise for 25 to 50 minutes depending upon their level of fitness. Interval training to improve aerobic power should involve low or high-intensity intervals of at least 60 to 90 seconds duration, with 1 to 2 minutes recovery in between

intervals. The coach could design the number and length of both training and rest intervals. Do not increase the time or distance by more than 10 to $20 \%$ each week. For example, if the athletes begin exercising for 10 minutes each session, only add 1to 2 minutes each week for the first couple months. It's smarter to go a little slow in the beginning. Even if the athletes feel could progress more quickly, the muscles and joints take longer to adapt to the stress of training than the heart and lungs.

Warm-up makes athlete workout feel smoother, prevents injuries, and helps the body move efficiently from a low to high metabolic state. Perform the activity will be doing for aerobic conditioning at a much lower level for about 5 to 10 minutes, or longer. Gradually increase the intensity of training until in target training range. The athletes can also include some flexibility training as part of warm-up. After warm-up a bit, stretch the muscles that will use during the activity.

Cool-down is a gradual reduction in the intensity of training. This helps bring blood that has been sent to the working muscles back into normal circulation. If athletes are jogging, gradually decrease pace and then walk for 5 to 10 minutes at the end of session. If athletes are cycling, reduce the pedaling speed or bike resistance during the last 5 to 10 minutes of training. The end of a workout is a great time to stretch to improve overall flexibility, because muscle 
temperature and blood flow are high. Strengthening training may also be done at this time.

\section{CONCLUSION}

From the above tables shows that muscle strength, explosive power, flexibility and coordination of male of Indonesia rugby athletes for Asian Games 2018 are good, meanwhile their cardio endurance are less.

\section{REFERENCES}

[1] Baechle T, R\& Roger, E, W, (2008). Essentials of Strength Training and Conditioning (3rd ed). United States: Human Kinetics
[2] Beginener's Guide to Rugby Union. International Rugby Board. (2016). Dublin-Ireland: St. Stephen's Green.

[3] Bompa.O,T, G \& Haff ,G. (2009). Periodization, Theory and Methodology of Training (5th ed). United States: Human Kinetics

[4] Brukner, K,P, ( 2007). Clinical Sport Medicine (3rd ed). Canberra: McGraw-Hill

[5] Cox, R, (2007). Sport Psychology: Concept and Application (6th ed). New York: McGraw Hill

[6] Gore, C, J, (2000). Physiological Test for Elite Athletes, Australia: Human Kinetics

[7] Nazir, M, (2003). Metoda Penelitian, Jakarta: Ghalia

[8] Powers K. H \& Edward T. S, (2007). Exercise Physiology, New York: McGraw-Hill Companies

[9] Putrawan,I,M, (1990). Pengujian Hipotesis Dalam Penelitian-Penelitian Sosial, Jakarta: Rineka Cipta 